for both short-term visits by individual scientists to lecture, to conduct seminars, to survey research, or to exchange professional views and, for longer stays of up to I year, to carry out laboratory research or investigations in the field. Visits in each direction, totalling approximately 40 man-months per annum, are provided under the programme, with no necessary matching of either the number of exchanges or the scientific fields in which they occur. In addition to its provisions for the exchange of individual scientists, the agreement provides for cooperation between the two Academies in the field of scientific publications and documentation, including the exchange of information on research and documentation and programmes, and mutual assistance and advice on the exchange of books and scientific literature. This agreement is similar to the agreement which came into effect on January 1 between the U.S. National Academy of Sciences and the Council of Academies of Yugoslavia. Similar arrangements are also anticipated between the U.S. National Academy of Sciences and the academies of Romania, Hungary and Czechoslovakia.

\section{Polish Academy of Sciences: Four-year Plan}

THE basic provisions of the 1966-70 Plan of the Polish Academy of Sciences Agencies are outlined by W. Nowacki in the Academy's Review for April-June, 1965 (10, No. 2; 38 ). The twenty-one institutes and forty-nine autonomous centres and agencies of the Academy now employ 5,600 persons, including 2,210 scientific workers, of whom 460 are independent; by 1970 it is anticipated that the present shortages in some disciplines will have been eliminated. In the social sciences, the research and development plan will continue the policy initiated a few years ago, but special attention will be given to the further development of the economic sciences. The establishment of an Institute for the Economic Sciences is proposed, as also is the development of research in pedagogios and psychology. In the biological sciences, the importance of biochemical and biophysical research is emphasized, and the development of microbiology and genetics is proposed. In medical and agricultural science and forestry, collaboration with the biological sciences will be strengthoned, and research on the nervous system, on experimental and transplantation surgery, the physiology of ageing and of labour, and on human geneties, medical anthropology and human ocology is specially mentioned. In physics, special attention will be given to the development of the physics of solids, quantum electronics and tho physics of low temperatures. In physical chemistry, the mechanism and laws of physico-chemical change, the methodology of separating multi-component mixtures, the physico-chemical foundations of metallic corrosion and the erosion of structural materials will be studied. In organic chemistry, the mechanism of reactions, the kinetics and catalysis of organic reactions, the utilization of indigenous raw materials and physiologically active substances are among the subjects proposed for research. Work on the physics of the rare and radioactive olements and the chemistry of plasma is also proposed. Research is also to be concentrated on the application of large automatic systems, new applications for analogue computers, the modelling of neuronal systems and on the methodology of planning.

\section{The Cumberland Basin, Bristol}

AlL large cities in Britain are to-day faced with an ever-growing traffic problem, and in this Bristol is no exception. In recent years, especially near tho city centro and the city docks, traffic conditions at certain times became quite chaotic, particularly when the old swing bridge was opened at intervals during the day to permit the passage of shipping in and out of the docks. This swing bridge was the focal point for an enormous flow of traffic from tho North, the Midlands, South Wales and
South-West England; when ships were moving in and out of dock, road traffic built up into queues stretching for miles along either side of the Cumberland Basin. The problem has been considerably eased, however, by completion of what is known as the Cumberland Basin Bridges Scheme, a brilliantly conceived and executed design of bridges, viaduets and a now swing bridge, an account of which is contained in an illustrated article entitled "The Cumberland Basin Bridges and Viaducts", recently published (Concrete Quarterly. No. 66; July-September 1965. London: Cement and Concrete Association. 5s.).

The new lay-out is essentially an interchange of elevated roads on which north-south traffic crosses the river on the Avon Bridge, a three-span pre-stressed concrete structure. On the north bank of the river is constructed a spiral slip road and a branched ramp which take traffic to and from the old swing bridge. Just north of this interchange is the new swing bridge carrying the road across the entrance lock. Then, just north of this, the carriageways divide into four separate lanes; north-bound traffic can go straight on into Bristol City, or it can turn westward down a curving ramp towards Avonmouth via the Avon Gorge; two more curved ramps carry southbound traffic up on to the new swing bridge. It is here that the swing bridge control tower is situated, whence changeable signs are operated to divert traffic streams down ramps towards the old swing bridge (east end of Cumberland Basin) when the new swing bridge is open for shipping. This most informative article gives technical details of the designs of the viaducts, the new Avon Bridge, and the new swing bridge. Apart from a panoramic photograph of the entire project, taken from the heights of Clifton, which clearly shows how traffic can flow in all directions without interruption, there are also photograph $_{\mathrm{s}}$ of a scale model of this scheme and its orientation, and of the Avon Bridge. A material factor in the overall design is that it has vastly improved the approaches to the city and has transformed much that was ugly into something much more pleasing which harmonizes the dockland with the well-known picture westwards, ". . . the towering cliffs of the Avon Gorge and Brunel's dramatic suspension bridge".

\section{Improved Analysis of Earthquakes}

ACCORDING to a recent paper entitled "The Application of Phased Arrays to the Analysis of Seismic Body Waves", by J. W. Burtill and F. E. Whiteway (Phil. Trans. Roy. Soc., No. 1091, 258, 421-493. London: H.M.S.O., 1965. 44s.; 6.60 dollars), the analysis of seismic body waves (that is, waves which have travelled through the earth rather than over its surface) has been facilitated by the use of phased arrays. This method has enabled more data concerning natural earthquakes and explosions to be obtained than has been so using the more conventional three-component set of seismographs. The array may first be used (often by signal delay and addition) to cut out random noise and microseisms, and then as a velocity and azimuth filter to eliminate unwanted waves, so that signal recognition is vastly improved. By these methods and by the use of correlation techniques, the velocities of various pulses across the array and their arrival time at one particular seismometer can be determined accurately. This information may then be used for the determination of the Earth's crustal structure by well-known mothods. At ranges loss than $25^{\circ}$ seismograms are very complex. However, for ranges from $30^{\circ}$ to $90^{\circ}$ the effect of the propagation path has been shown to be small, and the results from explosions are in agreement with a simple symmetrical, impulsive source function. Nearly all natural earthquakes investigated, however, had asymmotrical source functions. At Yellowknife, waves having a length of at least $20 \mathrm{~km}$ have been observed and arrays of comparable dimensions are therefore necessary. Experimonts have been, and are boing, performed with line, 